Regular paper

\title{
A broadband multiple-input multiple-output loop antenna array for 5G cellular communications
}

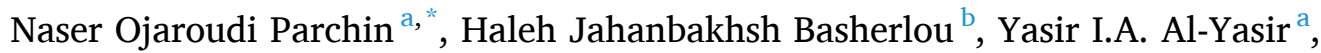 \\ Raed A. Abd-Alhameed ${ }^{\text {a }}$ \\ ${ }^{a}$ Faculty of Engineering and Informatics, School of Electrical Engineering and Computer Science, University of Bradford, Bradford BD7 1DP, UK \\ ${ }^{\mathrm{b}}$ Bradford College, Bradford, West Yorkshire BD7 1AY, UK
}

\section{A R T I C L E I N F O}

\section{Keywords:}

$5 \mathrm{G}$

Decoupling

Future mobile phones

Loop radiator

MIMO, phased array

\begin{abstract}
A B S T R A C T
In this study, we propose a multiple-input/multiple-output (MIMO) antenna array for fifth-generation (5G) mobile-phone applications. Its configuration is composed of eight planar loop antenna elements located at different edges of the mobile-phone mainboard with $75 \times 150 \times 0.8 \mathrm{~mm}^{3}$ FR-4 dielectric. In order to easily integrate with phone circuits, the ground-plane and antenna resonators have been etched on the same side of the substrate. By addling modified arrow-shaped strips among the adjacent loop antennas, the operation bandwidth and isolation level of the closely spaced radiators have been improved. The presented MIMO antenna is designed to cover the spectrum of commercial sub $6 \mathrm{GHz} 5 \mathrm{G}$ network with the bandwidth of 3.2-4 GHz. Due to the compact size and placements of the loop radiators, the presented MIMO antenna array occupies a small part of the board. In addition, the proposed array provides not only full radiation coverage covering different sides of the PCB but also the diversity function to support both vertical and horizontal polarization. The MIMO performance and radiation behavior of the proposed antenna design in the presence of the user-hand/user-head phantoms are also discussed. Moreover, a new and compact phased array millimeter-wave (MM-Wave) antenna with broad bandwidth and end-fire radiation is introduced to be easily integrated into the smartphone antenna system.
\end{abstract}

\section{Introduction}

The development of fifth-generation (5G) technology has been an ongoing process recently. It requires high data capacity and transmission speed [1,2]. Multiple-input-multiple-output (MIMO) is a promising technology to enhance the performance of $5 \mathrm{G}$ networks [3,4]. Although MIMO technology adds to the complexity of antenna design in terms of the number of antennas, it provides high data rates and improved spectral efficiency by exploiting multipath property without increasing the input power [5-7]. MIMO technology is currently used in fourthgeneration $(4 \mathrm{G})$ wireless systems because they can provide higher data rates at the fixed power and bandwidth levels when compared to their single-input-single-output (SISO) conventional counterparts. MIMO technology requires that all antenna radiators work simultaneously in which each antenna element of the system can work separately as transmitter and receiver [8]. In an ideal MIMO antenna system, the branch power ratio between the lowest and highest power levels within the antenna system should be $1(0 \mathrm{~dB})$ indicating that all antenna elements are receiving the same power which has been divided among all ports equally $[9,10]$. The use of MIMO antenna systems at the transmitter and the receiver sides needs careful consideration compared to their single antenna counterparts.

In order to have an efficient MIMO antenna system for user's devices, many challenges have to be addressed [11-13]. Among them is to design uncorrelated MIMO antenna elements in a confined space. Meanwhile, to ensure that the system has good MIMO performance, high isolation is required between antenna elements $[14,15]$. To maintain the independence of each antenna element in the MIMO system within a limited space, it is one of the urgent difficulties to overcome mutual coupling from the adjacent antenna elements [16,17]. Many techniques have been used to increase the isolation of MIMO elements while maintaining a compact design [18-20]. The most common technique is to use the spatial diversity technique by separating antenna elements. However, this technique may not be suitable for most user devices, since it requires a relatively large space to place the antenna system. We present here a new design method to enhance not only the isolation between these

\footnotetext{
* Corresponding author.

E-mail address: N.OjaroudiParchin@Bradford.ac.uk (N.O. Parchin).
} 


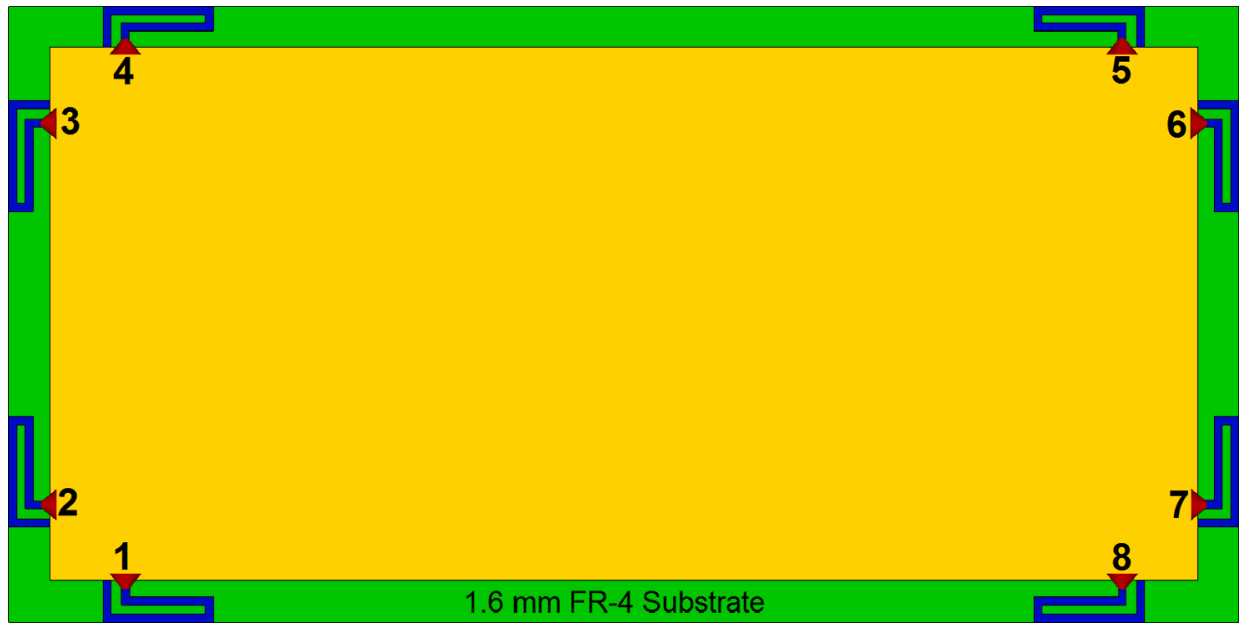

Fig. 1. Configuration of the mobile-phone antenna array with conventional loop radiators.

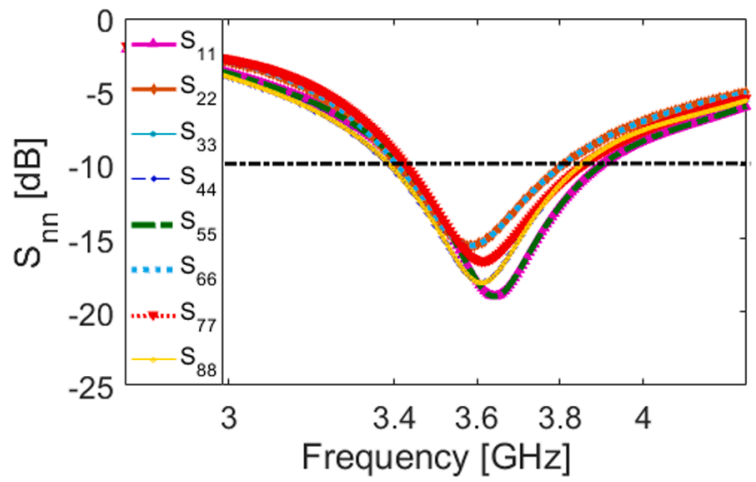

(a)

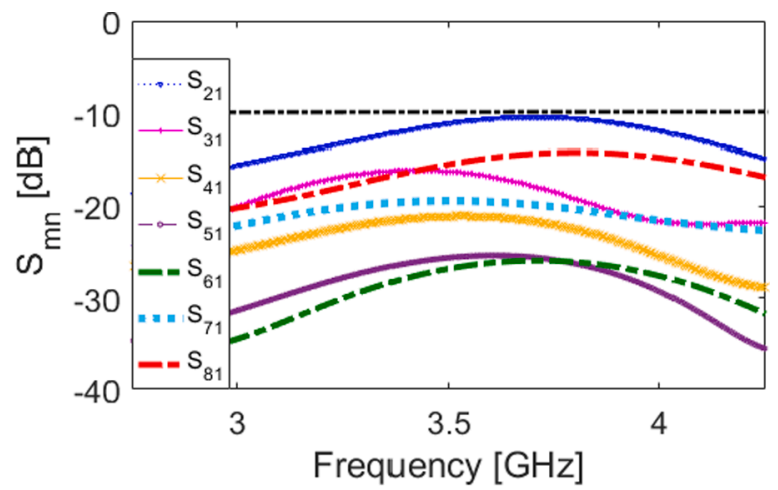

(b)

Fig. 2. Simulated (a) $S_{n n}$ and (b) $S_{m n}$.

closely spaced elements but also the bandwidth of the MIMO system for future $5 \mathrm{G}$ handsets. Several $5 \mathrm{G}$ smartphone antennas are proposed recently [21-37]. However, these antennas either provide narrow bandwidth with low isolation or occupy a huge space of mainboard or use uniplanar antenna radiators. In addition, most of the reported designs do not offer polarization and radiation diversity.

The antenna elements of the proposed MIMO design are loop resonators that have been fed by discrete ports extended from the ground plane to the radiators. The employed loop antennas are compact and easy to fabricate which could exhibit omnidirectional/quasi-

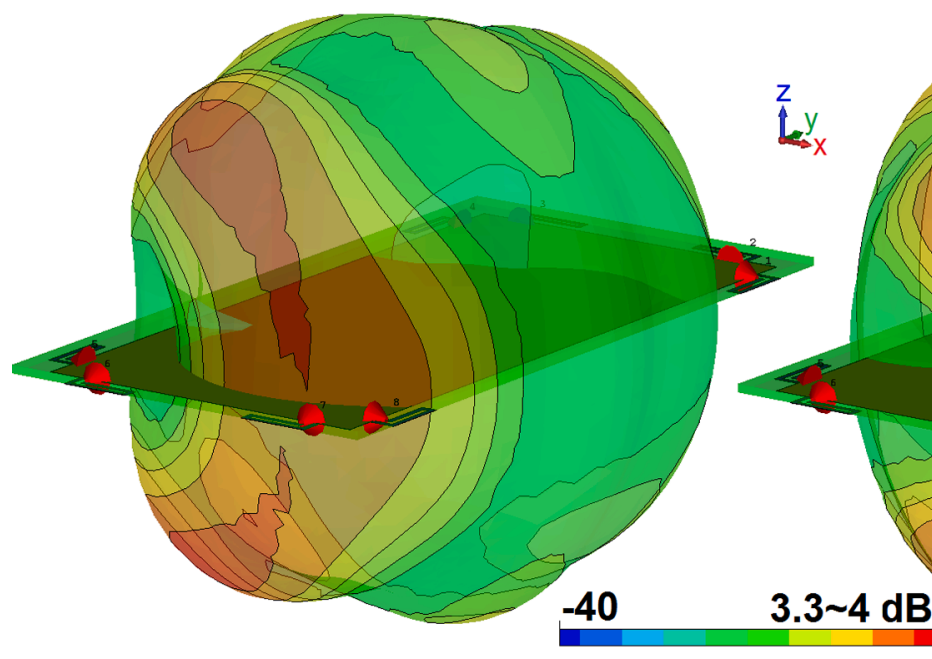

(a) (b)

Fig. 3. Radiation patterns at $3.6 \mathrm{GHz}$ from (a) Ant. 1 and (b) Ant. 2 . 


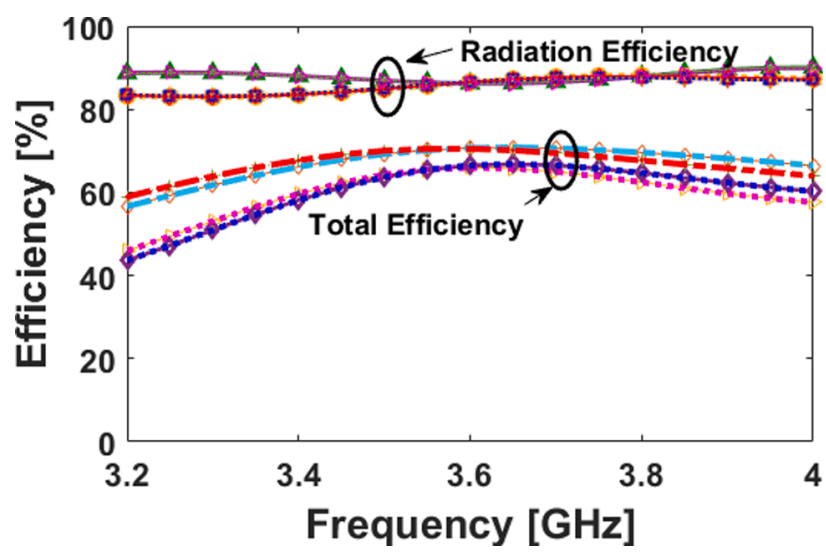

Fig. 4. Efficiencies of the MIMO design without decoupling strips.

omnidirectional radiation patterns and can be applied for different wireless systems $[38,39]$. In order to obtain a higher channel capacity, the polarization diversity function is applied in the proposed MIMO antenna design, so that all antenna elements can be allowed into the limited space of a smartphone, and good isolations have been obtained. The proposed MIMO system is mainly targeting at $3.6 \mathrm{GHz} 5 \mathrm{G}$ candidate band and uses eight-elements placed at different sides of the board [40]. By adding arrow strips among the elements, the bandwidth and isolation of the proposed antenna system are improved. It provides more than $800 \mathrm{GHz}$ bandwidth and sufficient mutual couplings less than $-11 \mathrm{~dB}$.

In addition to the proposed sub $6 \mathrm{GHz}$ MIMO smartphone antenna, a new and compact phased array with broad bandwidth and end-fire radiation is introduced for mm-wave $5 \mathrm{G}$ applications. Its configuration is composed of four loop dipole resonators with pairs of directors arranged in a linear form which can be easily integrated into the smartphone antenna system. This manuscript has been structured as below: The schematic and performance of conventional loop array are presented in Section 2. The design and characteristics of the proposed MIMO antenna systems with improved characteristics are represented in Section 3. Section 4 provides and compares the measurements with simulation. Section 5 compares the fundamental characteristics of the proposed MIMO antenna with the recently published MIMO antenna designs. Section 6 investigates the behavior of the designed array in the vicinity of the user. A new compact phased array antenna is proposed in Section 7 to be integrated into the smartphone board. Section 8 gives a conclusion of this manuscript.
Table 1

The values of the design parameters.

\begin{tabular}{lllllllll}
\hline Parameter & $\mathrm{W}$ & $\mathrm{W}_{1}$ & $\mathrm{~W}_{2}$ & $\mathrm{~W}_{3}$ & $\mathrm{~W}_{4}$ & $\mathrm{~W}_{5}$ & $\mathrm{~W}_{6}$ & $\mathrm{~W}_{7}$ \\
\hline Value $(\mathrm{mm})$ & 1.25 & 5 & 1 & 1.5 & 1.25 & 3 & 4 & 4 \\
Parameter & $\mathrm{W}_{8}$ & $\mathrm{~L}$ & $\mathrm{~L}_{1}$ & $\mathrm{~L}_{2}$ & $\mathrm{~L}_{3}$ & $\mathrm{~L}_{4}$ & $\mathrm{~L}_{5}$ & $\mathrm{X}$ \\
\hline Value $(\mathrm{mm})$ & 10 & 2 & 13.5 & 1 & 10.3 & 3.2 & 2 & 1.5 \\
\hline
\end{tabular}

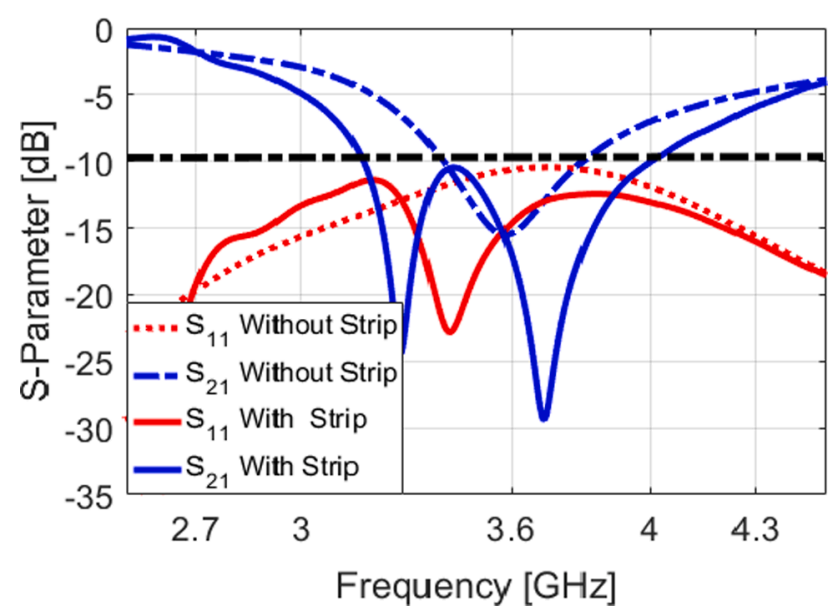

Fig. 6. $S_{11} / S_{21}$ of adjacent elements with and without the modified decoupling strip.

\section{Loop antenna array}

Fig. 1 shows the schematic of the proposed MIMO antenna system with eight loop antennas placed at four sides of the mainboard. The $S$ parameter results of the conventional loop design are depicted in Fig. 2. It is clearly shown that the loop elements provide $400 \mathrm{MHz}$ impedancebandwidth for $\mathrm{S}_{11} \leq-10 \mathrm{~dB}$ with the main resonance at $3.6 \mathrm{GHz}$ (5G candidate band). Moreover, the mutual coupling of the closely spaced resonators of the antenna elements is less than $-10 \mathrm{~dB}$.

$3 \mathrm{D}$ radiation patterns of the closely-spaced diversity loop elements including Antennas 1 and 2 at the resonance frequency $(3.6 \mathrm{GHz})$ are depicted in Fig. 3. It is seen that the antenna elements exhibit quasiomnidirectional radiations covering both portions of the mobile-phone mainboard [41-43]. The efficiency results of the MIMO antenna system are illustrated in Fig. 4. Moreover, as seen, the mobile-phone

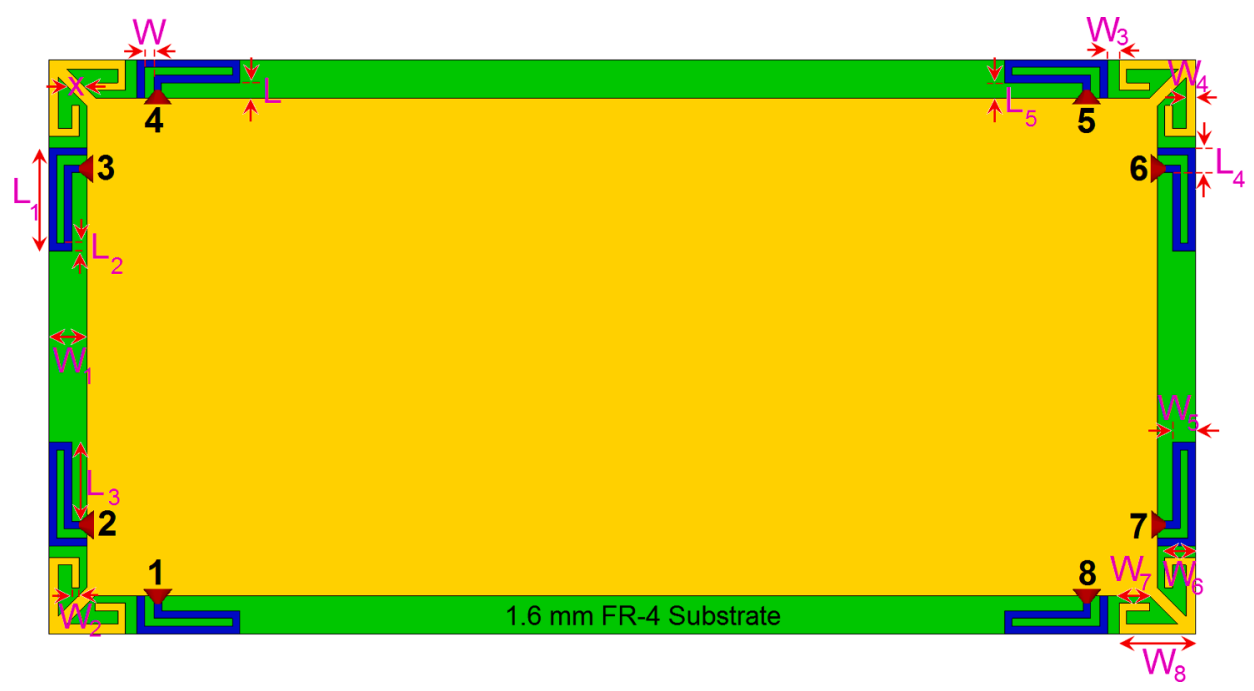

Fig. 5. The proposed 8-element smartphone diversity antenna. 


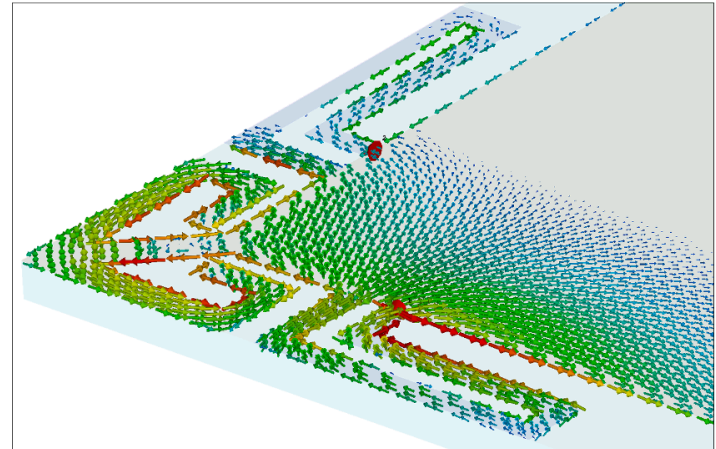

(a)

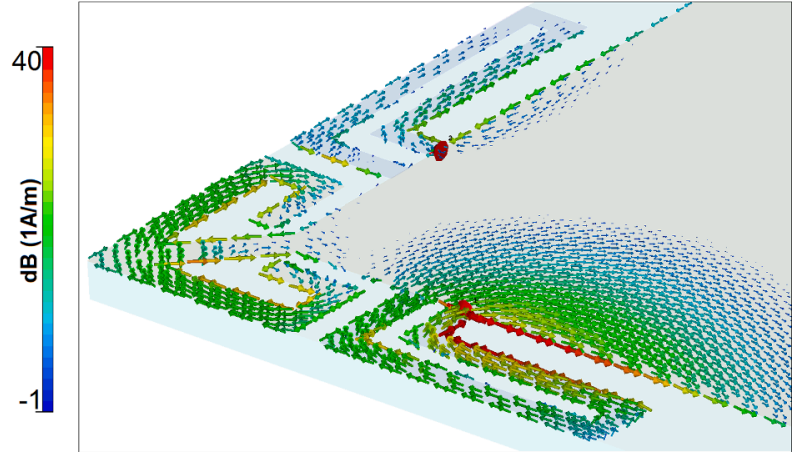

(b)

Fig. 7. Simulated current densities at (a) $3.3 \mathrm{GHz}$ and (b) $3.7 \mathrm{GHz}$.

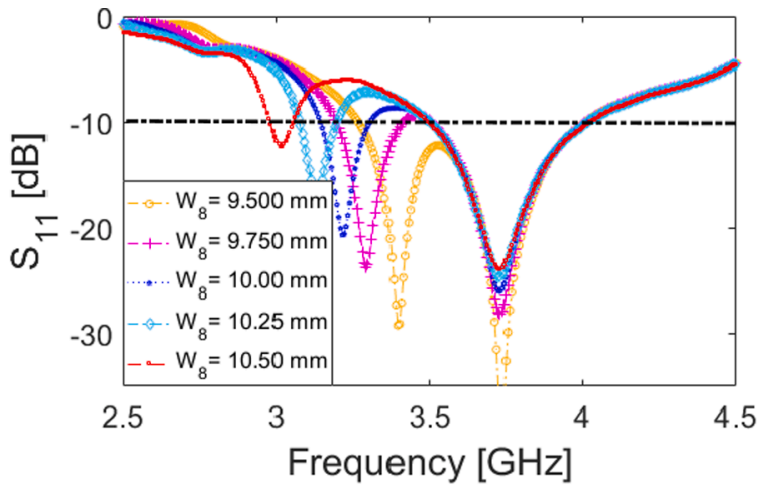

(a)

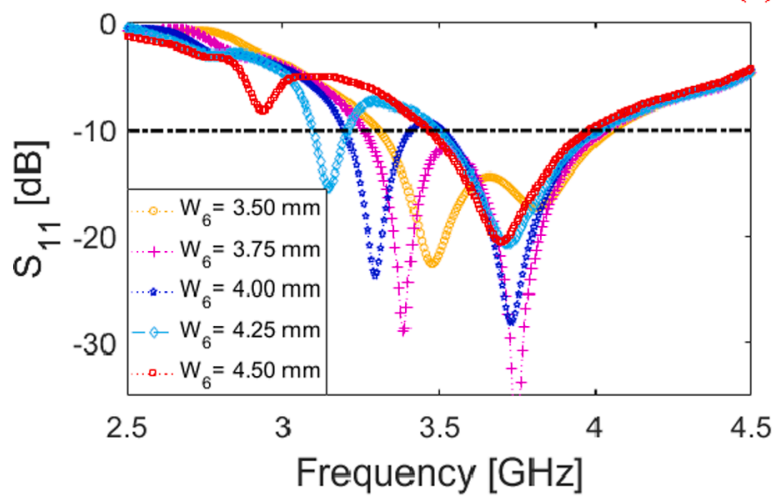

(b)
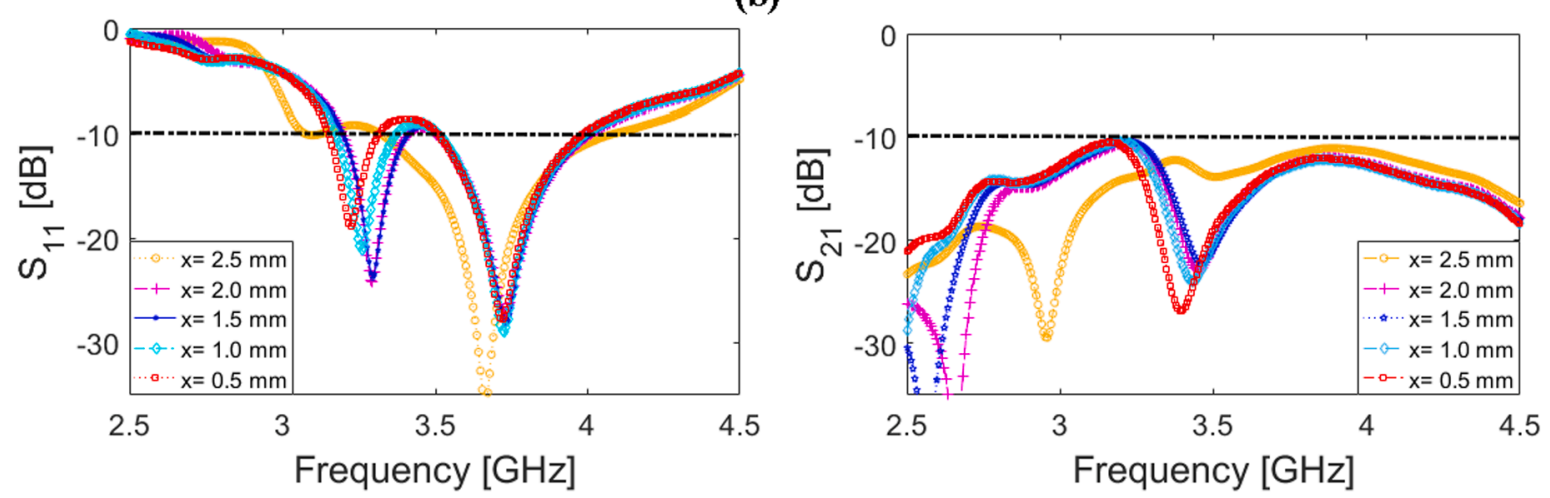

(c)
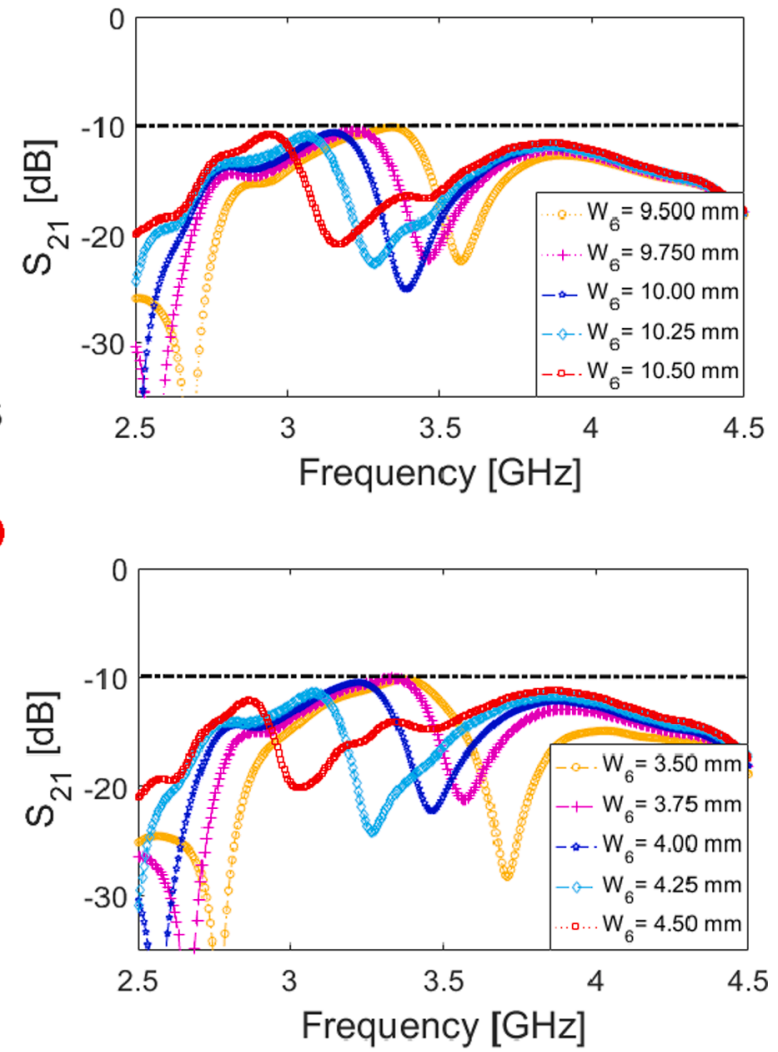

Fig. 8. $S_{11} / S_{21}$ of the antenna for different parameter values of the arrow-strip (a) $W_{8}$, (b) $W_{6}$, and (c) $x$. 


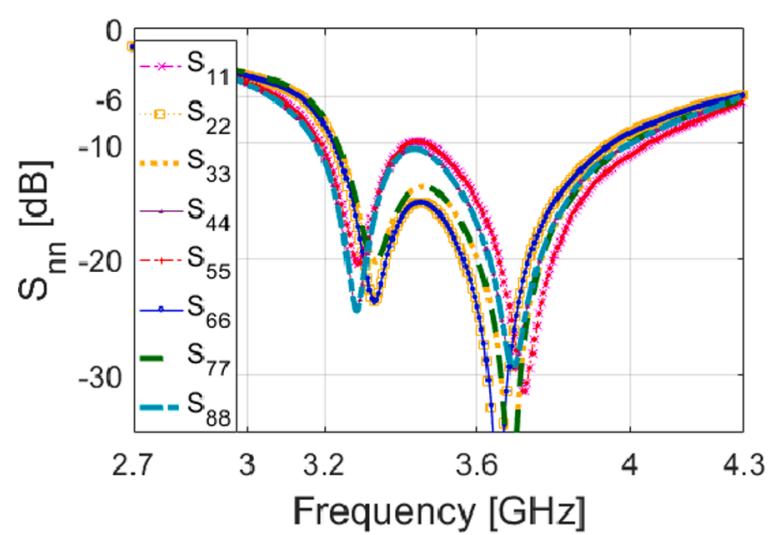

(a)

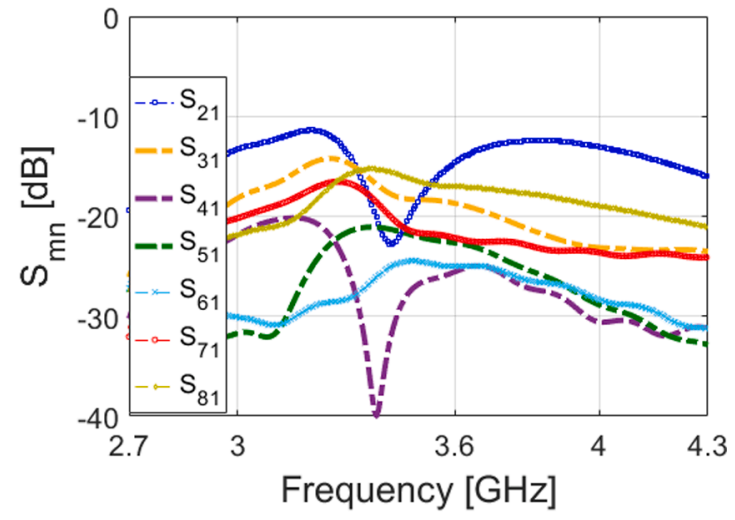

(b)

Fig. 9. Simulated (a) $S_{n n}$ and (b) $S_{m n}$ of the array S-parameters.

provides sufficient efficiencies. As illustrated, the obtained radiation and total efficiencies are more than $80 \%$ and $40 \%$, respectively.

\section{Characteristics of the presented MIMO diversity antenna system with improved performance}

The final structure of the proposed MIMO diversity antenna design is given in Fig. 5. The array is printed on a single-sided FR4 substrate with an overall size of the printed MIMO antenna is $75 \times 150 \mathrm{~mm}^{2}$. The large size of the ground plane could help to improve the isolation between elements and free up more space for other circuit components. Besides, to increase the frequency bandwidth and isolation of the radiators, modified arrow strips are inserted between adjacent elements, as illustrated in Fig. 5. Table 1 specifies the dimensions of the proposed MIMO smartphone antenna. Fig. 6 plots and compares the return loss $\left(\mathrm{S}_{11}\right)$ and mutual coupling $\left(\mathrm{S}_{21}\right)$ of two adjacent loop radiators without and with the modified arrow strip. It is shown that the arrow strip, placed between the elements, can act as a decoupling structure to increase the isolation between the antenna ports. Therefore, at $3.6 \mathrm{GHz}$ (5G candidate frequency), the mutual coupling is successfully reduced from -10 to less than $-15 \mathrm{~dB}$. Besides, at the operation bandwidth of the antenna, the mutual coupling function is less than $-11 \mathrm{~dB}$. Meanwhile, the employed strips improve not only the mutual coupling of the array but also the frequency bandwidth of the design. As seen, compared with the conventional design (shown in Fig. 2), the operation band of the proposed MIMO diversity antenna has been increased significantly. The proposed design is covering $800 \mathrm{MHz}$ in the frequency spectrum of 3.2-4 GHz. Nevertheless, for $S_{11} \leq-6 \mathrm{~dB}$, the loop antenna element is supporting the operation band of $3-4.3 \mathrm{GHz}$.

In order to have a better illumination about the working mechanism of the loop radiator, the simulated current distributions at $3.3 \mathrm{GHz}$ and 3.7 GHz are represented in Fig. 7 (a) and (b), respectively. As shown at $3.3 \mathrm{GHz}$, the current is mainly distributed near the modified arrow strip, which verifies the role of the strip in creating a new resonance at 3.3 GHz. While at $3.7 \mathrm{GHz}$, the currents are mainly concentrated inside of the loop resonator [44-47].

As mentioned earlier, using arrow strips among adjacent loop antennas, the operation band and isolation level of the radiators have been significantly improved. Also, the frequency behavior of the design is flexible and can be easily adjusted to the desired operation band $[48,49]$. Fig. 8 represents a detailed parametric study of the decupling structure (arrow-strip) and the influence of its size changes on the Sparameters of the antenna. The results of varying design parameters including $\mathrm{W}_{8}, \mathrm{x}$, and $\mathrm{W}_{6}$ are shown in Fig. 8(a)-(c), respectively. It is evident that any changes in the values of the strip parameters mainly affect the first resonance as well as the mutual coupling of the antenna
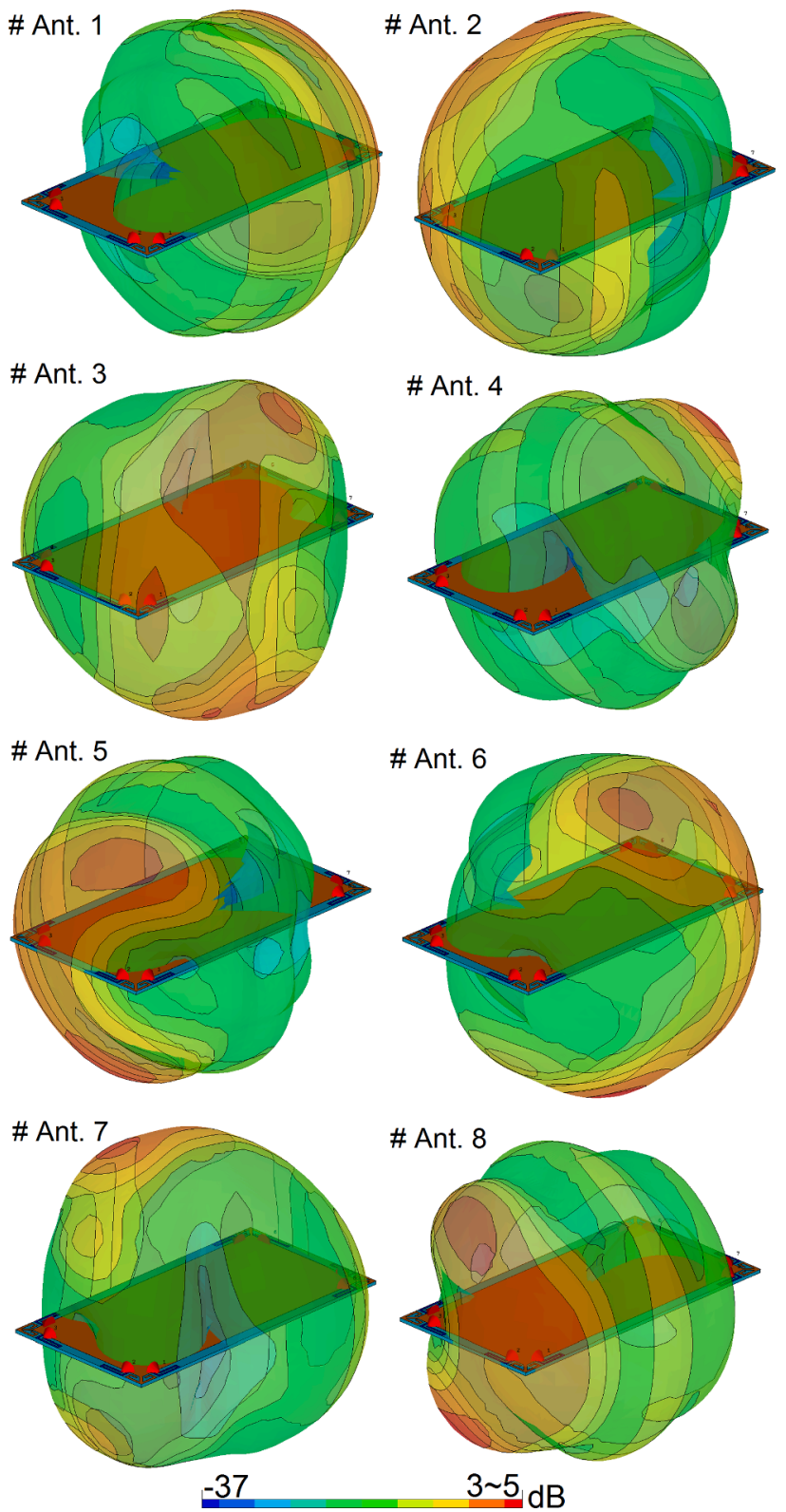

Fig. 10. Radiation patterns of diversity loop element at $3.6 \mathrm{GHz}$. 


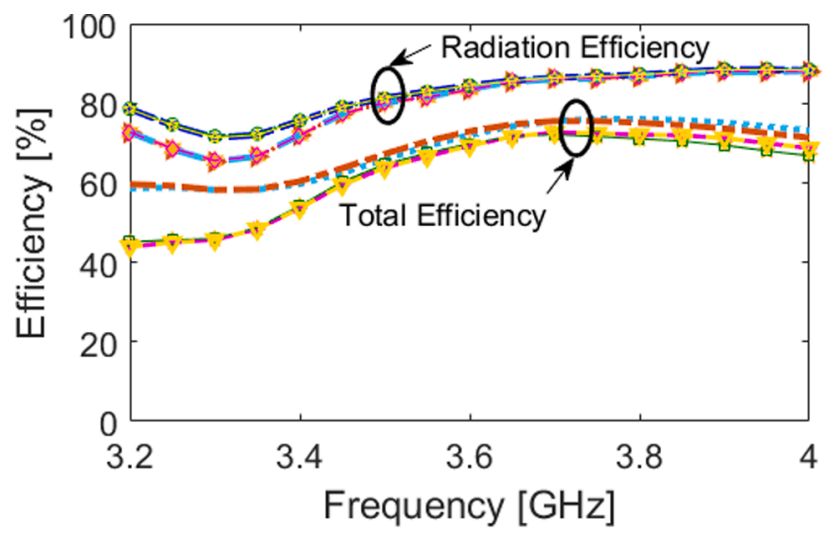

Fig. 11. Efficiencies of the MIMO diversity mobile-phone antenna.

elements [50]. As seen in Fig. 8(a) and (b), when the sizes of strip-arm parameters $\left(\mathrm{W}_{8} \& \mathrm{~W}_{6}\right)$ changes from 9.5 to $10.5 \mathrm{~mm}$ and 3.5 to 4.5 $\mathrm{mm}$, the lower resonance frequency of the antenna decreases from 3.4 to $3 \mathrm{GHz}$. This also affects the mutual coupling $\left(\mathrm{S}_{21}\right)$ of the antenna whereas the lower mutual coupling of the antenna shifted to lower frequencies when $\mathrm{W}_{8} \& \mathrm{~W}_{6}$ changed. However, unlike the arm parameters of the decoupling structure, changing the width of the protruded branch (x) does not affect the antenna performance significantly. Fig. 8 (c) plots the antenna $S_{11} / S_{21}$ changes for different values of $x$. As shown, for different values of $\mathrm{x}$, fewer variations are observed for the antenna operation band and mutual coupling which is not significant compared with the results shown in Fig. 8(a) and (b).

Fig. 9 illustrates $S_{n n}$ (reflection coefficient) and $S_{m n}$ (mutualcoupling) characteristics of the smartphone antenna array. As seen from Fig. 9(a), good S parameter results with a wide operation band of 800 $\mathrm{MHz}(3.2-4 \mathrm{GHz})$ for $\mathrm{S}_{\mathrm{nn}} \leq-10$ and $1300 \mathrm{MHz}(3-4.3 \mathrm{GHz})$ for $\mathrm{S}_{\mathrm{nn}} \leq-6$ $\mathrm{dB}$ are achieved for the design. Moreover, it provides sufficient mutual couplings between the elements, as depicted in Fig. 9(b).

3D transparent views of the radiation patterns at $3.6 \mathrm{GHz}$ for each feeding port have been illustrated in Fig. 10. It is observed that the loop resonators not only could cover different sides of the mobile-phone board but also support different polarizations which is a unique function for MIMO design [51,52]. It is seen that the 8-element MIMO antenna can offer a sufficient gain value for each radiator. The gain characteristic of the modified loop antenna elements is about $2-5 \mathrm{~dB}$.

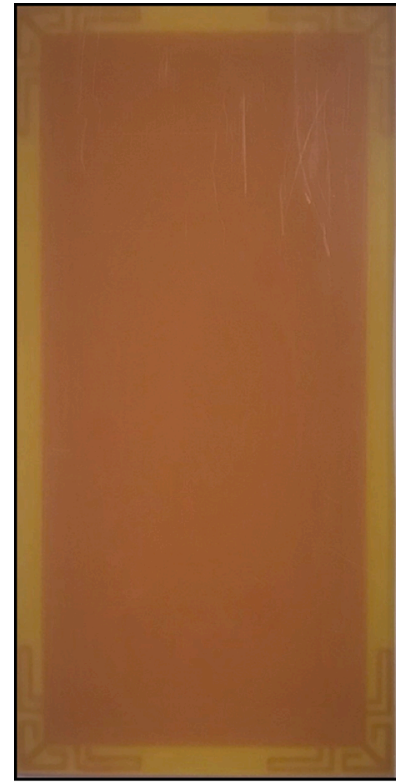

(a)

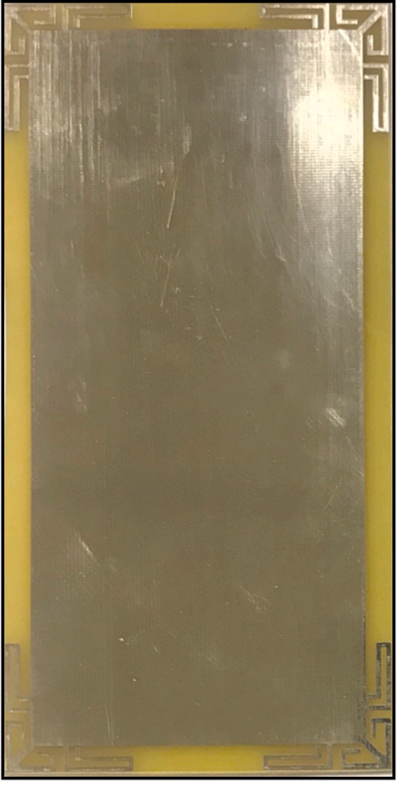

(b)

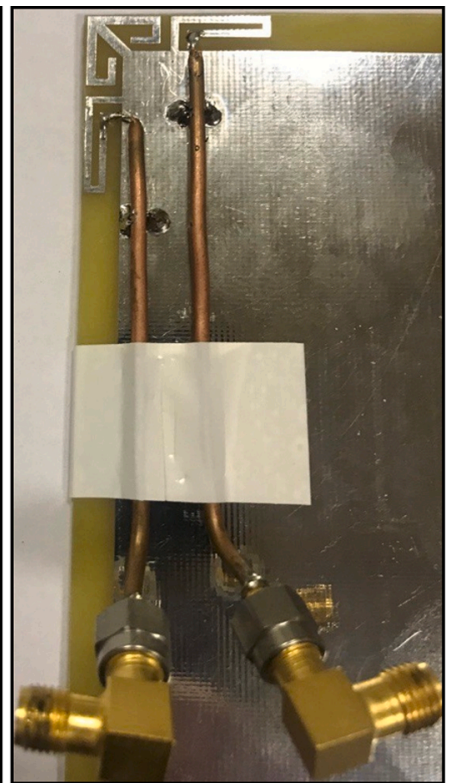

(c)

Fig. 12. (a) Front (b) back views of the fabricated sample, and (c) the feeding mechanism of the adjacent antennas.

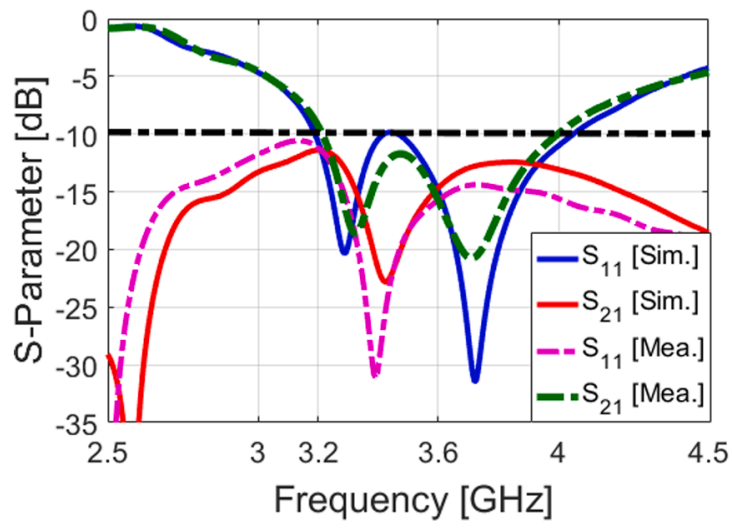

(a)

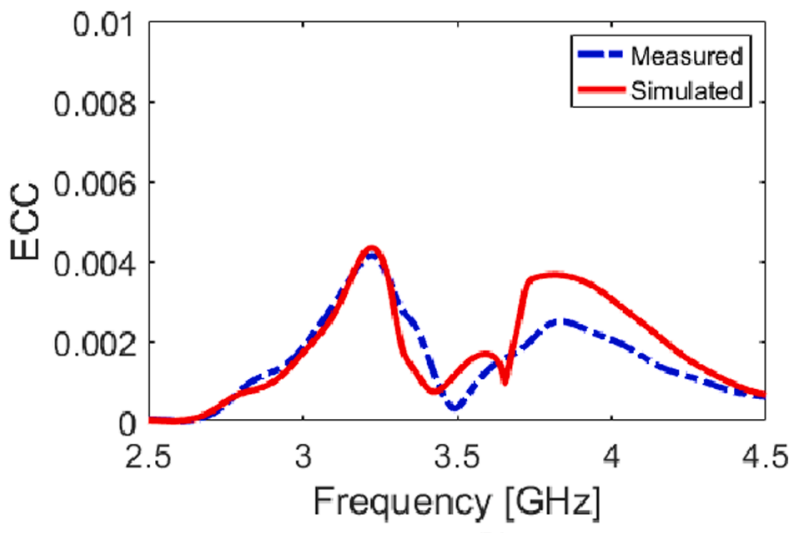

(b)

Fig. 13. Measured and simulated (a) $S_{11} / S_{21}$ and (b) ECC results of the two adjacent resonators. 


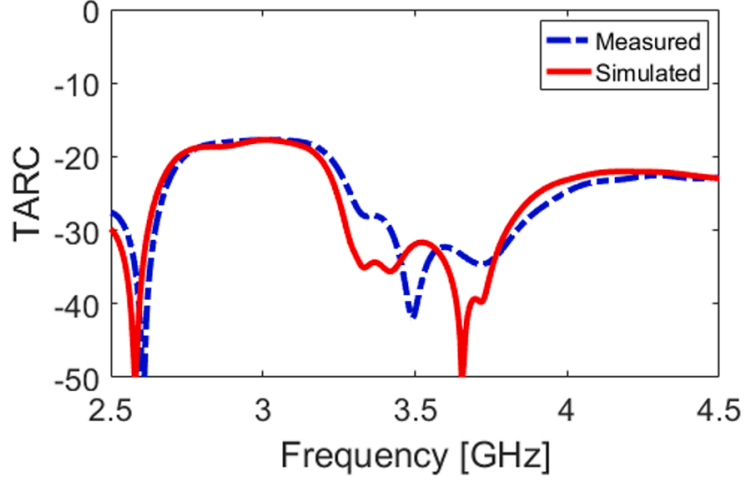

(a)

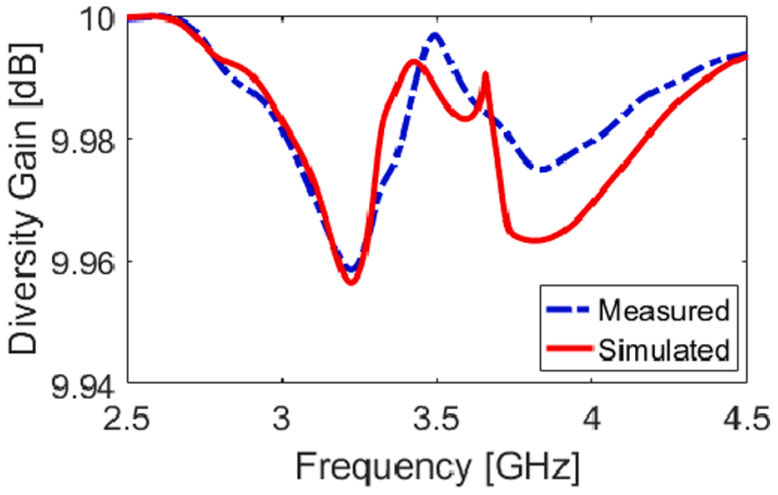

(b)

Fig. 14. Calculated (a) TARC and (b) DG results of the two adjacent resonators.

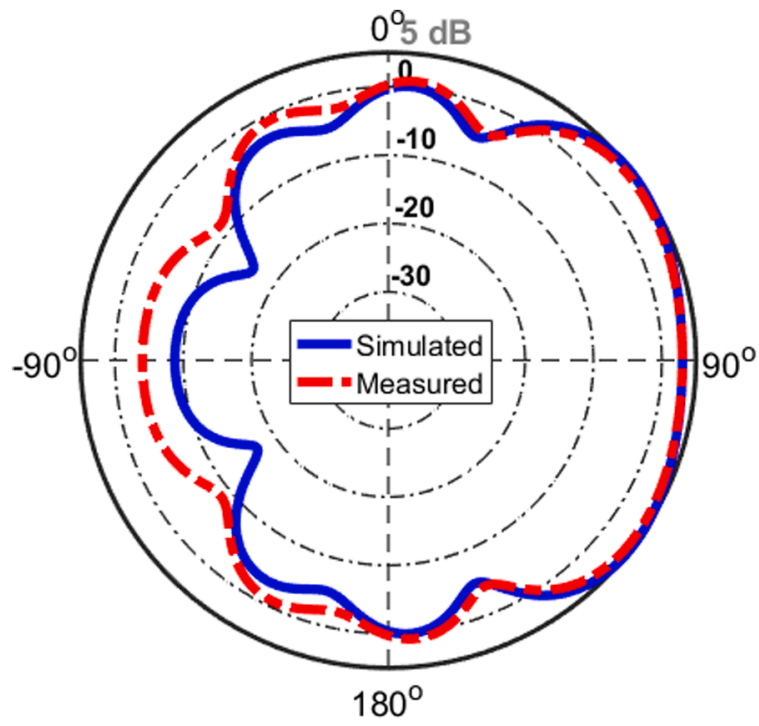

(a)

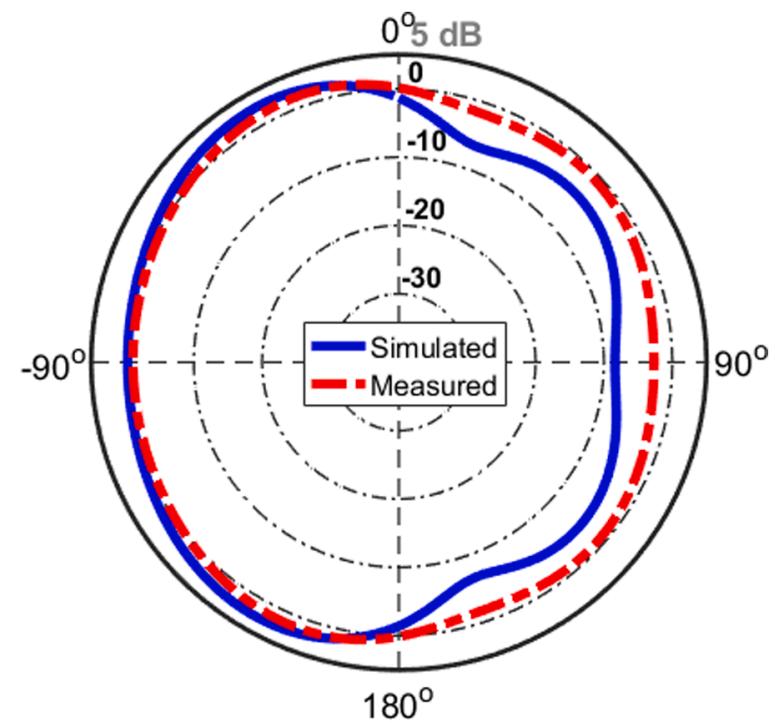

(b)

Fig. 15. Comparison of measured and simulated radiation patterns of the elements from ports (a) 1 and (b) 2 .

Moreover, four horizontally and four vertically polarized radiation patterns are observed which could improve the MIMO performance of the design. The efficiencies (radiation and total) of the MIMO antenna system are also illustrated in Fig. 11. It is shown that sufficient efficiency results are obtained within the operation band of 3.2-4 GHz. Also, as shown, for the range of $3.4-4 \mathrm{GHz}$, more than $80 \%$ radiation and $60 \%$

Table 2

Comparison of the proposed antenna system with the recently reported smartphone antennas.

\begin{tabular}{|c|c|c|c|c|c|c|}
\hline Reference & Antenna Type & Bandwidth (GHz) & Efficiency (\%) & Size $\left(\mathrm{mm}^{2}\right)$ & Isolation $(\mathrm{dB})$ & ECC \\
\hline [21] & Coupled IFA & $3.4-3.6$ & - & $150 \times 75$ & 15 & $<0.02$ \\
\hline$[22]$ & Inverted-F & $3.4-3.6$ & $55-60$ & $100 \times 50$ & 10 & - \\
\hline$[23]$ & Patch-Slot & $3.55-3.65$ & $52-76$ & $150 \times 75$ & 11 & - \\
\hline [24] & Monopole & $3.4-3.6$ & $35-50$ & $150 \times 75$ & 11 & $<0.40$ \\
\hline$[25]$ & Spatial-Reuse Antenna & $3.4-3.6$ & $40-70$ & $150 \times 75$ & 12 & $<0.2$ \\
\hline [26] & L-shaped Monopole & $3.4-3.6$ & $40-60$ & $136 \times 68$ & 14 & $<0.2$ \\
\hline [27] & Inverted-F-Shaped & $3.4-3.6$ & - & $120 \times 70$ & 20 & - \\
\hline$[28]$ & Ring-Slot & $3.4-3.8$ & $60-75$ & $150 \times 75$ & 15 & $<0.01$ \\
\hline [29] & Monopole & $4.55-4.75$ & $50-70$ & $136 \times 68$ & 10 & - \\
\hline$[30]$ & Tightly Arranged Pairs & $3.4-3.6$ & $50-70$ & $150 \times 73$ & 17 & $<0.07$ \\
\hline [31] & Waveguide & $3.4-3.6$ & $50-80$ & $150 \times 75$ & 15 & $<0.2$ \\
\hline [32] & Monopole & $3.4-3.6$ & $60-70$ & $150 \times 75$ & 18 & $<0.01$ \\
\hline [33] & Balanced Open Slot & $3.4-3.6$ & $65-75$ & $150 \times 75$ & 17 & $<0.05$ \\
\hline [34] & Open-End Slot & $3.4-3.6$ & $50-60$ & $136 \times 68$ & 11 & $<0.05$ \\
\hline [35] & Loop Radiator & $3.3-3.6$ & 40 & $120 \times 70$ & 15 & $<0.02$ \\
\hline [36] & Dongle Resonator & $3.4-3.6$ & $50-73$ & $130 \times 65$ & 15 & - \\
\hline [37] & Patch-Slot & $3.4-3.8$ & $50-65$ & $150 \times 75$ & 12 & $<0.01$ \\
\hline This Work & Diversity loop & $3.2-4$ & $50-75$ & $150 \times 75$ & 11 & $<0.005$ \\
\hline
\end{tabular}



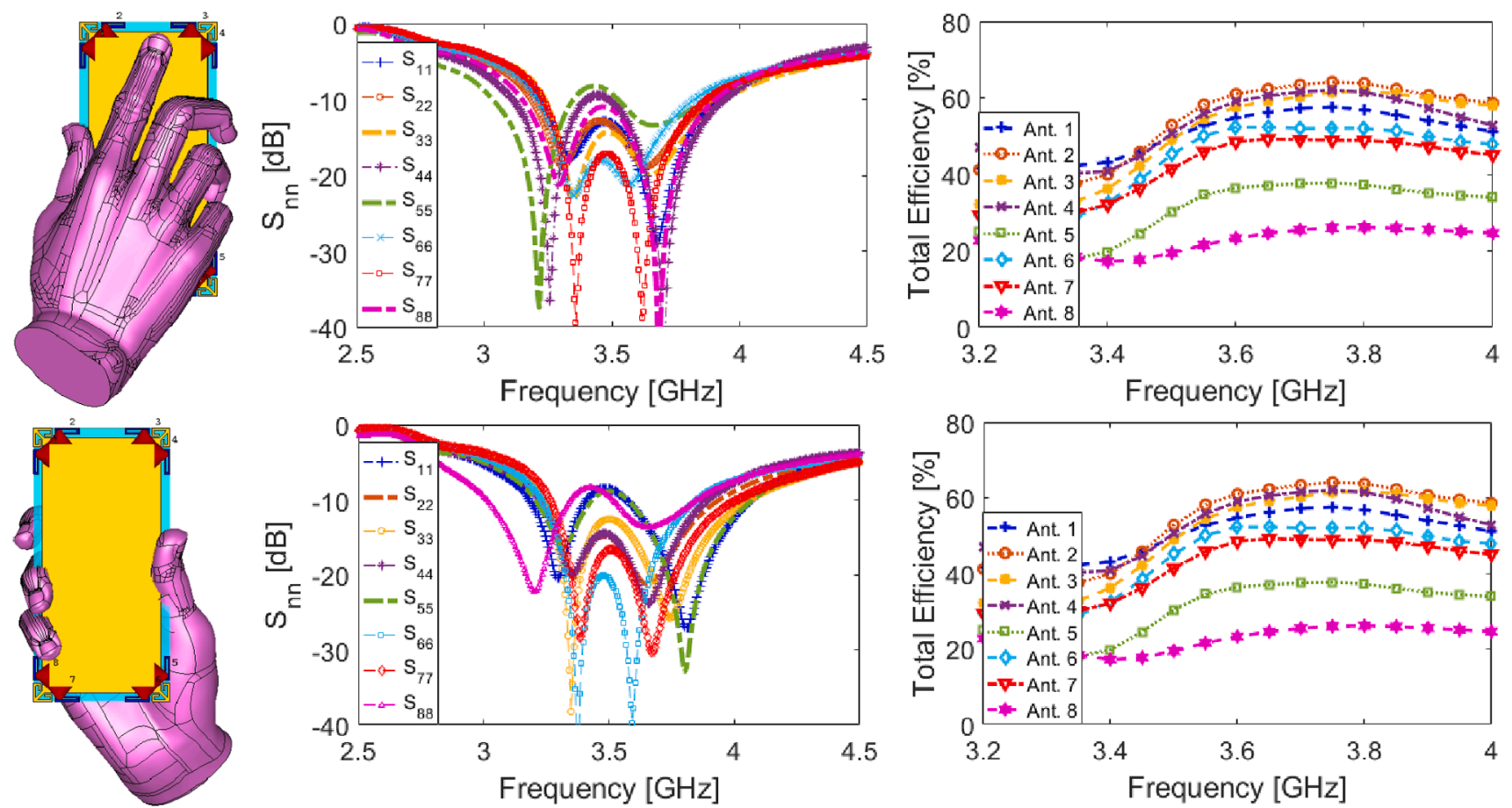

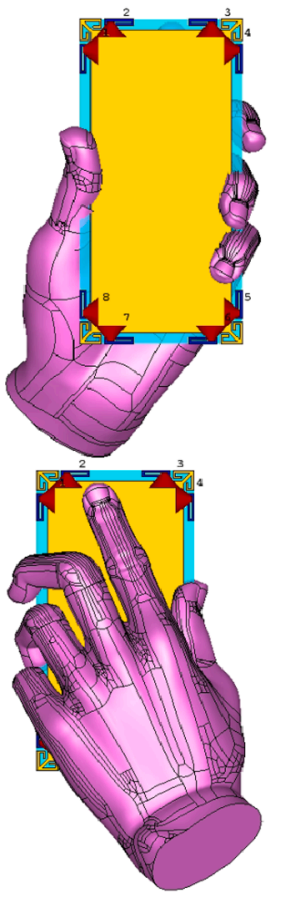

(a)
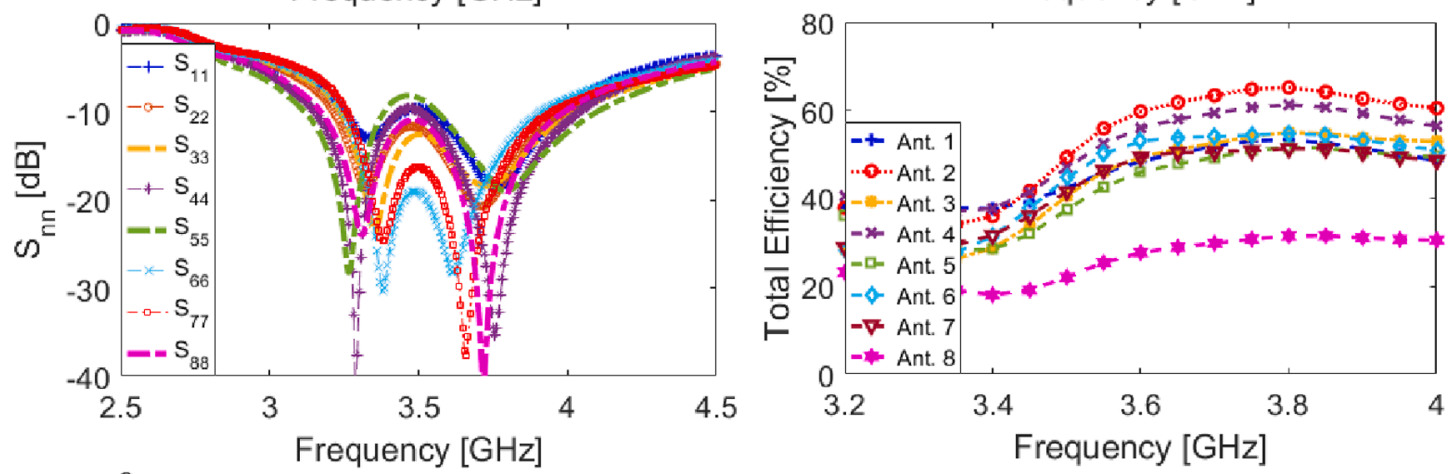

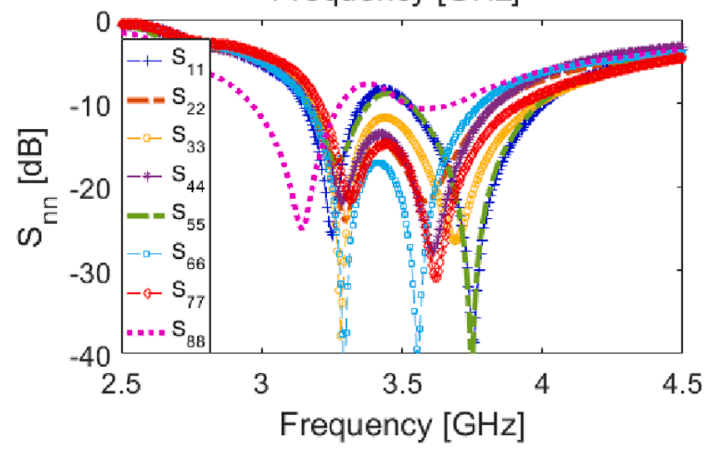

(b)

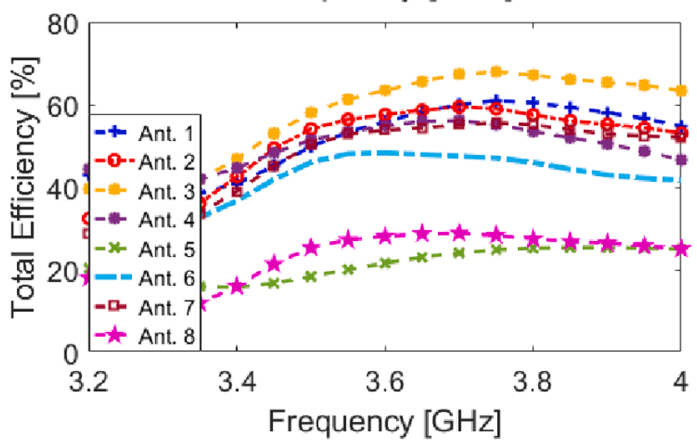

(c)

Fig. 16. (a) Placement, (b) $\mathrm{S}_{\mathrm{nn}}$, and (c) efficiencies of the designed MIMO antenna array at studied user-hand scenarios.

total efficiencies can be observed for the proposed MIMO antenna.

\section{Measurements and discussion}

A prototype sample of the $5 \mathrm{G}$ smartphone antenna array was fabricated, as shown in Fig. 12(a) and (b). Due to similar placements and performances of the loop antenna pairs, the properties of the smartphone antenna design for port 1 and 2 are measured and discussed in the following. The feeding mechanism of the adjacent loop antenna elements is depicted in Fig. 12(c).

The measured and simulated results of the S-parameters are compared in Fig. 13(a). As seen, the measurements have an agreement with the simulated results to cover the required operation band: a quite good frequency bandwidth $\left(3.2-4 \mathrm{GHz}\right.$ for $\left.S_{11}<-10 \mathrm{~dB}\right)$, and mutual coupling $\left(\mathrm{S}_{21}<-11 \mathrm{~dB}\right)$ are obtained for the antenna elements. The envelope correlation coefficient (ECC), total active reflection coefficient (TARC), and diversity gain (DG) specifications are important parameters in diversity/MIMO antennas to justify that the antenna elements are competent for diversity reception/transmission in the MIMO channels [53]. Fig. 13 (b) represents the calculated ECC results of the MIMO array. It is seen that the calculated ECC characteristics of the array are low within the frequency band with a maximum value of less than 0.005 . Fig. 14(a) and (b) plot the TARC and DG results, respectively. As seen, the TARC results are less than $-25 \mathrm{~dB}$ at $3.2-4 \mathrm{GHz}$ (antenna operation 


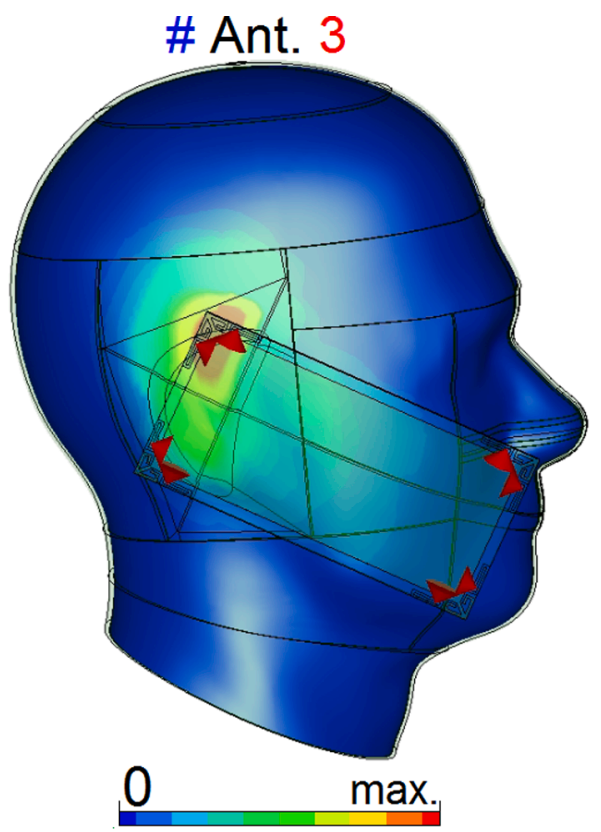

(a)

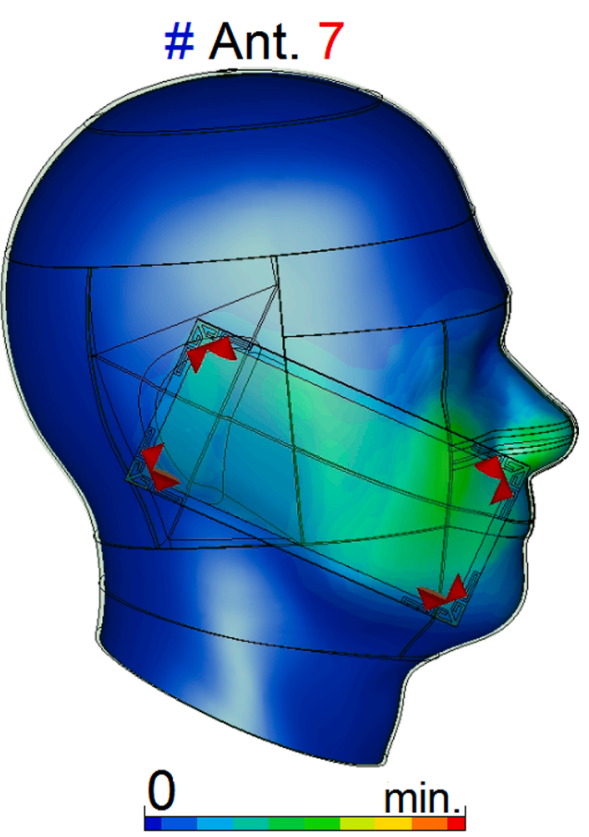

(b)

Fig. 17. SAR results of (a) Ant. 3 and (b) Ant. 7 in Talk-Mode.

band). Furthermore, it is shown in Fig. 14(b), the DG function is more than $9.96 \mathrm{~dB}$.

Measured and simulated 2D-polar radiation patterns of the closelyspaced loop antennas are shown in Fig. 15. It should be noted during the measurements, we keep one port excited and another one loaded with a $50-\Omega$ load. As seen from Fig. 15(a) and (b), the prototype offers good quasi-omnidirectional radiation patterns at $3.6 \mathrm{GHz}$ (middle frequency) with the acceptable agreement between simulations and measurements $[54,55]$.

\section{Comparison}

The characteristics of the presented array antenna with recently reported designs [21-37] are compared and listed in Table 2. It is evident that our designed MIMO antenna system offers better performances in terms of impedance match and bandwidth, and its clearance size keeps at a satisfactory level. In addition, the proposed design achieves not only around $0.8 \mathrm{GHz}$ impedance bandwidth but also sufficient mutual couplings, better than $-11 \mathrm{~dB}$. Besides, unlike the reported $5 \mathrm{G}$ antenna design, the structure of the proposed smartphone antenna is planar, and it is implemented in one-side of the smartphone mainboard which makes it easy to be fabricated and integrated with the circuit.

\section{User-effect investigation}

The health hazard of emitted electromagnetic (EM) radiation from smartphones has become a point of open deliberation as the use of mobile handset is increasing exponentially [56]. In the following, different usage postures in data-mode of the user-hand for right and left hands touching top/bottom sides of the smartphone are considered and investigated in Fig. 16. According to the obtained results, the proposed design exhibits similar radiation behavior for different hand scenarios. This is mainly due to the symmetrical schematic of the designed antenna system. As shown, the smartphone antenna and its loop elements exhibit good efficiencies $(20-65 \%)$. It worth noting that the maximum reductions of the radiation performance are discovered for the resonators that have been partially covered by the hand-phantom [57].

The EM energy absorbed by human body tissues can be evaluated by the specific absorption rate (SAR) [58]. It is a measure of how much power is being absorbed per unit mass. The SAR feature of the MIMO design is represented in Fig. 17: It is shown that Ant. 3 causes the maximum SAR value and the minimum SAR value is observed from Ant.

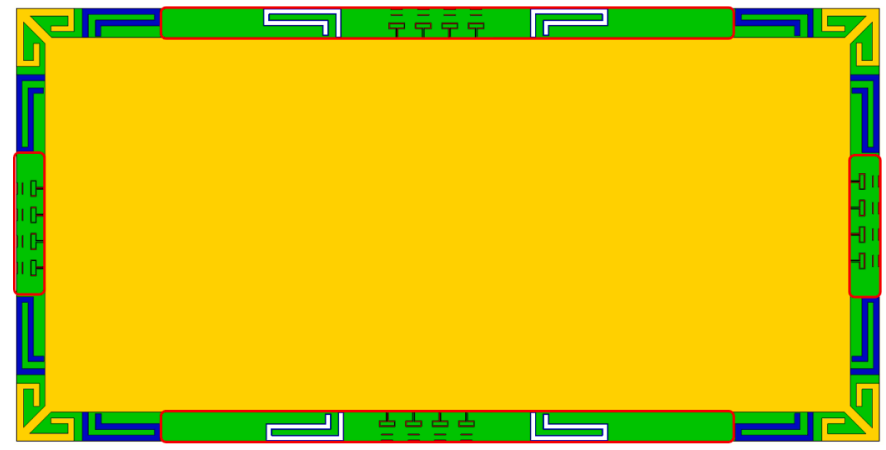

(a)

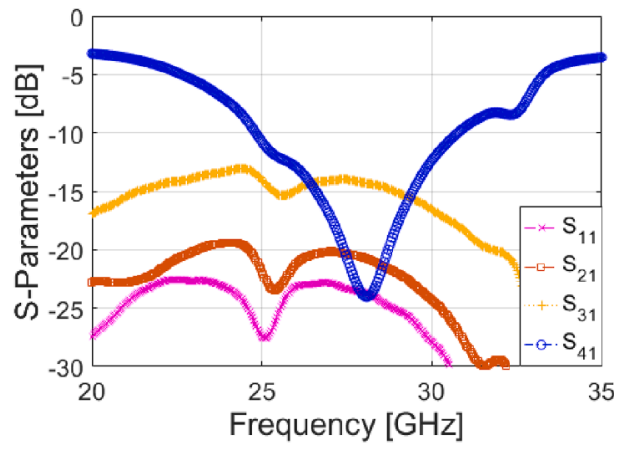

(b)

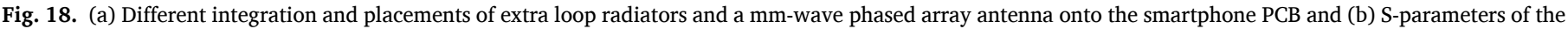
mm-wave phased array. 


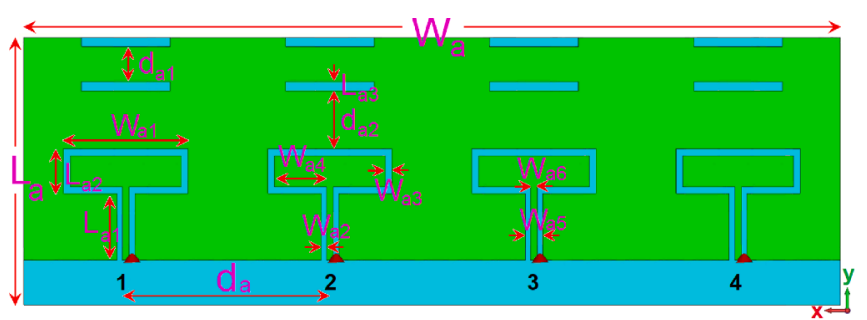

(a)

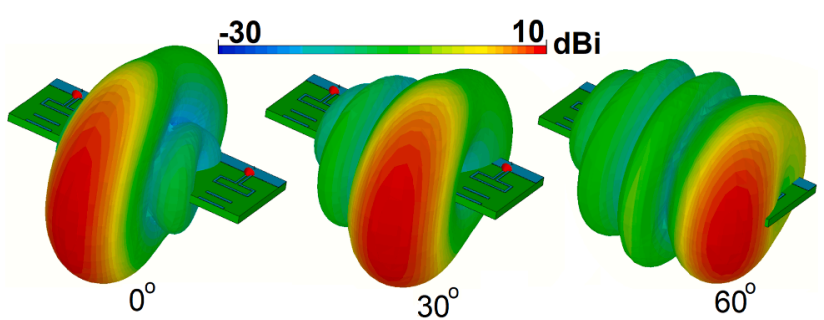

(b)

Fig. 19. (a) Design details and configuration of the mm-wave phased array antenna and (b) its beam-steering function at different angles.

7. Therefore, it can be concluded that the distance of the loop antenna elements with the head phantom is playing the main role in the value of the SAR function.

\section{Integration of a compact mm-wave phased array}

Due to the compact sizes of the employed loop radiators, the number of the radiators in the configuration of the proposed smartphone antenna can be easily increased without any change or effect on the placement and performance of the other elements. As clearly shown in Fig. 18(a), by adding other pairs of loop radiators at right and left sides of the smartphone mainboard (illustrated in white colour), the MIMO configuration of the proposed antenna can be increased to $12 \times 12$ which could improve the performance of the system and makes it more suitable for massive MIMO applications [59,60]. However, the fundamental antenna parameters such as impedance bandwidth, mutual coupling, and MIMO characteristics such as ECC and TARC results should be investigated.

Apart from the sub $6 \mathrm{GHz}$ spectrum, the 5G smartphones are also expected to support the MM-Wave spectrum [61-64]. Phased array antennas with high performances are highly desirable for mm-wave 5G communications since they can increase the radiation and the connectivity of the system [65-66]. In the following, a new and miniaturized mm-wave phased array $5 \mathrm{G}$ antenna with broad bandwidth is proposed to be incorporated in a shared case. Due to the low-profile of the designed phased array with four radiators, it can be placed at different four sides (including top/bottom portions or right/left sides) of the PCB, as shown in Fig. 18(a). The phased array is designed to work at $28 \mathrm{GHz}$, one of the promising $5 \mathrm{G}$ candidate bands at higher frequencies $[67,68]$. However, due to broad bandwidth characteristic, the proposed phased array is capable to cover 26 and $30 \mathrm{GHz} 5 \mathrm{G}$ bands. Fig. 18(b) plots the Sparameters $\left(S_{11} \sim S_{41}\right)$ of the phased array. As seen, the designed phased array provides a broad impedance bandwidth of $25-31 \mathrm{GHz}$ with a center frequency of $28 \mathrm{GHz}$. Besides, as shown, less than $-14 \mathrm{~dB}$ mutual coupling characteristic is obtained for the antenna elements.

The design details of the integrated phased array is illustrated in Fig. 19(a). It has a very compact size with an overall size of $\mathrm{W}_{\mathrm{a}} \times \mathrm{L}_{\mathrm{a}}=18$ $\times 5 \mathrm{~mm}^{2}$. As shown its configuration is composed of four loop dipole resonators with pairs of directors arranged in a linear form. The parameter values (in $\mathrm{mm}$ ) are as follow: $\mathrm{W}_{\mathrm{a} 1}=2.8, \mathrm{~W}_{\mathrm{a} 2}=0.125, \mathrm{~W}_{\mathrm{a} 3}=$ $0.15, \mathrm{~W}_{\mathrm{a} 4}=1.8, \mathrm{~W}_{\mathrm{a} 5}=0.4, \mathrm{~W}_{\mathrm{a} 5}=0.15, \mathrm{~L}_{\mathrm{a} 1}=1, \mathrm{~L}_{\mathrm{a} 2}=1.5, \mathrm{~L}_{\mathrm{a} 3}=0.2, \mathrm{~d}_{\mathrm{a}}$ $=0.125, \mathrm{~d}_{\mathrm{a} 1}=0.8, \mathrm{~d}_{\mathrm{a} 2}=1.3$. The $3 \mathrm{D}$ beam steering function of the array at $28 \mathrm{GHz}$ for different angles are plotted in Fig. 19(b). As shown, the designed phased array provides a good beam-steering function with endfire radiation beams with high gains and low sidelobes $[69,70]$.

\section{Conclusion}

A 5G smartphone antenna array with improved characteristics is introduced in this paper. Four pairs of the discrete-fed loop antennas are placed at four corners of the mainboard to form an $8 \times 8$ MIMO array. By adding modified arrow strips between adjacent elements, the frequency bandwidth and isolation level of the MIMO system are improved.
Fundamental characteristics and MIMO performance of the design are investigated. It offers good characteristics in terms of bandwidth, isolation, and radiation pattern. A prototype sample of the design was fabricated and characteristics of two adjacent loop antenna elements have been measured. Furthermore, the characteristics of the design in the presence of the user are discussed. In addition, a low-profile mmwave phased array with end-fire radiation is introduced to be integrated into the smartphone PCB.

\section{Declaration of Competing Interest}

The authors declare that they have no known competing financial interests or personal relationships that could have appeared to influence the work reported in this paper.

\section{Acknowledgments}

This work is supported by the European Union's Horizon 2020 research and innovation program under grant agreement H2020-MSCAITN-2016 SECRET-722424.

\section{References}

[1] Nadeem QUA, et al. Design of $5 \mathrm{G}$ full dimension massive MIMO systems. IEEE Trans Commun 2018;66:726-40.

[2] Yang HH, Quel YQS. Massive MIMO meet small cell. Springer Briefs Electr Comput Eng 2017.

[3] Franco De F, Llui J, Jordi R, Alfred G. Multiantenna systems for MIMO communications. Morgan \& Claypool; 2013.

[4] Osseiran A, et al. Scenarios for $5 \mathrm{G}$ mobile and wireless communications: the vision of the METIS project. IEEE Commun Mag 2014;52:26-35.

[5] Ojaroudi N, Ghadimi N. Design of CPW-fed slot antenna for MIMO system applications. Microw Opt Technol Lett 2014;56:1278-81.

[6] Yang Q, et al. Heterogeneous semi-blind interference alignment in finite-SNR networks with fairness consideration. IEEE Trans Wireless Commun 2020;19: $2472-88$.

[7] Yu H, et al. Online resource allocation for Energy harvesting based large-scale multiple antenna systems. Globecom workshops (GC Wkshps), Waikoloa, HI, USA. 2019.

[8] Sharawi MS. Advancements in MIMO antenna systems. Developments in antenna analysis and synthesis. IET; 2018 [Chapter-4].

[9] Kildal PS. Foundations of antenna engineering. Artech House; 2015.

[10] Abraray A, et al. A metamaterial-inspired small rectenna for RF energy harvesting based on a 3-Way power combiner. Global communications conference (GLOBECOM). 2019.

[11] Hussain R, Alreshaid AT, Podilchak SK, Sharawi MS. Compact 4G MIMO antenna integrated with a 5G array for current and future mobile handsets. IET Microw Antennas Propag 2017;11:271-9.

[12] Parchin NO, Abd-Alhameed RA. A compact Vivaldi antenna array for 5 G channel sounding applications. London (UK): EuCAP; 2018.

[13] Mazloum J, et al. Compact triple-band S-shaped monopole diversity antenna for MIMO applications. Appl Comput Electromagn Soc J 2015;30:975-80.

[14] Elfergani ITE, et al. Antenna fundamentals for legacy mobile applications and beyond. Springer Nature; 2017. p. 1-659.

[15] Hong W, Baek K, Lee Y, Kim Y, Ko S. Study and prototyping of practically largescale mmWave antenna systems for 5 G cellular devices. IEEE Commun Mag 2014; 52(9):63-9.

[16] Ojaroudi N, et al. Quadband planar inverted-f antenna (PIFA) for wireless communication systems. Progr Electromagn Res Lett 2014;45:51-6.

[17] Chen $Q$, et al. Single ring slot based antennas for metal-rimmed $4 \mathrm{G} / 5 \mathrm{G}$ smartphones. IEEE Trans Antennas Propag 2018;67:1476-87.

[18] Iqbal A, Saraereh OA, Ahmad AW, Bashir S. Mutual coupling reduction using Fshaped stubs in UWB-MIMO antenna. IEEE Access 2018;6:2755-99. 
[19] Farahani MM, Akbari M, Sebak A, et al. Mutual coupling reduction in millimeterwave MIMO antenna array using a metamaterial polarization-rotator wall. IEEE Antennas Wireless Propag Lett 2017;16:2324-7.

[20] Ramachandran A, Pushpakaran S, Pezholil M, Kesavath V. A four-port MIMO antenna using concentric square-ring patches loaded with CSRR for high isolation. IEEE Antennas Wirel Propag Lett 2016;15:1196-9.

[21] Liu Y, et al. MIMO antenna array for 5 G smartphone applications. 13th European conference on antennas and propagation (EuCAP), Krakow, Poland. 2019.

[22] Al-Hadi AA, Ilvonen J, Valkonen R, Viikan V. Eight-element antenna array for diversity and MIMO mobile terminal in LTE 3500MHz band. Microwave Opt Technol Lett 2014;56:1323-7.

[23] Ojaroudi Parchin N, et al. Dual-polarized MIMO antenna array design using miniaturized self-complementary structures for $5 \mathrm{G}$ smartphone applications. 13th European conference on antennas and propagation (EuCAP), 31 March-5 April 2019, Poland. 2019.

[24] Wong KL, et al. 8-antenna and 16-antenna arrays using the quad-antenna linear array as a building block for the 3.5-GHz LTE MIMO operation in the smartphone. Microw Opt Technol Lett 2016;58:174-81.

[25] Chang LY, et al. Polarization-orthogonal co-frequency dual antenna pair suitable for 5G MIMO smartphone with metallic bezels. IEEE Trans Antennas Propag 2019; 67:5212-20.

[26] Abdullah M, et al. Eight-element antenna array at 3.5GHz for MIMO wireless application. PIER C 2017;78:209-17.

[27] Zhao X, Yeo SP, Ong LC. Decoupling of inverted-F antennas with high-order modes of ground plane for 5G mobile MIMO platform. IEEE Trans Antennas Propag 2018; 66:4485-95.

[28] Parchin NO, et al. Eight-element dual-polarized MIMO slot antenna system for $5 \mathrm{G}$ smartphone applications. IEEE Access 2019;9:15612-22.

[29] Xu S, Zhang M, Wen H, Wang J. Deep-subwavelength decoupling for MIMO antennas in mobile handsets with singular medium. Sci Rep 2017;7:12162.

[30] Sun L, Feng H, Li Y, Zhang Z. Compact 5G MIMO mobile phone antennas with tightly arranged orthogonal-mode pairs. IEEE Trans Antennas Propag 2018;66: 6364-9.

[31] Li M-Y, et al. Tri-polarized 12-antenna MIMO array for future 5G smartphone applications. IEEE Access 2018;6:6160-70.

[32] Zhao A, Zhouyou R. Size reduction of self-isolated MIMO antenna system for 5G mobile phone applications. IEEE Antennas Wirel Propag Lett 2019;18:152-6.

[33] Li Y, Sim C-Y-D, Luo Y, Yang G. High-isolation 3.5 GHz eight-antenna MIMO array using balanced open-slot antenna element for $5 \mathrm{G}$ smartphones. IEEE Trans Antennas Propag 2019;67:3820-30.

[34] Abdullah M, et al. High-performance multiple-input multiple-output antenna system for $5 \mathrm{G}$ mobile terminals. Electronics 2019;8(1090):1-16.

[35] Jiang W, Liu B, Cui Y, Hu W. High-isolation eight-Element MIMO array for 5G smartphone applications. IEEE Access 2019;7:34104-12.

[36] Parchin NO, et al. $8 \times 8$ MIMO antenna system with coupled-fed elements for $5 \mathrm{G}$ handsets. IET Antennas and propagation conference. November 2019, Birmingham, UK. 2019.

[37] Chen WS, Lai YC, Sim CYD. MIMO dongle antenna design for next generation mobile communication system. In: IEEE international conference on computational electromagnetics (ICCEM) 2017; 2017. p. 320-2.

[38] Ojaroudi N, et al. Enhanced bandwidth of small square monopole antenna by using inverted Ushaped slot and conductor-backed plane. Appl Comput Electromagn Soc (ACES) J 2012;27:685-90.

[39] Musavand A, et al. A compact UWB slot antenna with reconfigurable band-notched function for multimode applications. Appl Comp Electromagn Soc J 2016;31:14-8.

[40] Statement: Improving consumer access to mobile services at $3.6 \mathrm{GHz}$ to $3.8 \mathrm{GHz}$. Available online: https://www.ofcom.org.uk/consultations-and-statements/categ ory-1/future-use-at-3.6-3.8-ghz [accessed on 21 October 2018].

[41] Parchin NO, et al. MM-wave phased array quasi-yagi antenna for the upcoming 5G cellular communications. Appl Sci 2019;9:1-14.

[42] Ullah A, et al. Coplanar waveguide antenna with defected ground structure for $5 \mathrm{G}$ millimeter wave communications. IEEE MENACOMM'19, Bahrain. 2019.

[43] Ojaroudi N, Ghadimi N. Dual-band CPW-fed slot antenna for LTE and WiBro applications. Microw Opt Technol Lett 2014;56:1013-5.

[44] Abdulkhaleq AM, Parchin NO, et al. Mutual coupling effect on three-way doherty amplifier for green compact mobile communications. EuCAP 2020, Copenhagen, Denmark. 2020.
[45] Ojaroudi N, et al. Quad-band planar inverted-f antenna (pifa) for wireless communication systems. Progr Electromagn Res Lett 2014;45:51-6.

[46] Ojaroudi N, et al. An omni-directional PIFA for downlink and uplink satellite applications in C-band. Microw Opt Technol Lett 2014;56:2684-6.

[47] Siahkal-Mahalle BH, et al. A new design of small square monopole antenna with enhanced bandwidth by using cross-shaped slot and conductor-backed plane. Microwave Opt Technol Lett 2012;54:2656-9.

[48] Ojaroudi M, et al. Dual band-notch small square monopole antenna with enhanced bandwidth characteristics for UWB applications. Appl Comput Electromagn Soc (ACES) J 2012;27:420-6.

[49] Al-Yasir YI, et al. A new polarization-reconfigurable antenna for $5 \mathrm{G}$ applications. Electronics 2018;7:293.

[50] Ojaroudi N. Circular microstrip antenna with dual band-stop performance for ultrawideband systems. Microw Opt Technol Lett 2014;56:2095-8.

[51] Al-Nuaimi MKT, Whittow WG. Performance investigation of a dual element ifa array at $3 \mathrm{ghz}$ for mimo terminals. In: Antennas and propagation conference (LAPC), Loughborough, UK; 2011. p. 1-5.

[52] Ojaroudiparchin N, Shen M, Pedersen GF. Small-size tapered slot antenna (TSA) design for use in 5G phased array applications. Appl Comput Electromagn Soc J 2018;32:193-202.

[53] Sharawi MS. Printed multi-band MIMO antenna systems and their performance metrics [wireless corner]. IEEE Antennas Propag Mag 2013;55:218-32.

[54] Valizade A, et al. Band-notch slot antenna with enhanced bandwidth by using $\Omega$-shaped strips protruded inside rectangular slots for UWB applications. Appl Comput Electromagn Soc (ACES) J 2012;27:816-22.

[55] Ojaroudi N. Design of microstrip antenna for 2.4/5.8 GHz RFID applications. German microwave conference, GeMic 2014, RWTH Aachen University, Germany, March 10-12, 2014. 2014.

[56] Syrytsin I, Zhang S, Pedersen GF. Performance investigation of a mobile terminal phased array with user effects at $3.5 \mathrm{GHz}$ for LTE advanced. IEEE Antennas Wirel Propag Lett 2017;16:1847-50.

[57] Ojaroudiparchin N, et al. A switchable 3-D-coverage-phased array antenna package for 5G mobile terminals. IEEE Antennas Wireless Propag Lett 2016;15:1747-50.

[58] Khan R, et al. User influence on mobile terminal antennas: A review of challenges and potential solution for 5G antennas. IEEE Access 2018;6:77695-715.

[59] Bang J, Choi J. A SAR reduced mm-wave beam-steerable array antenna with dualmode operation for fully metal-covered 5G cellular handsets. IEEE Antennas Wirel Propag Lett 2018;17(6):1118-22.

[60] Li Y, et al. 12-port 5G massive MIMO antenna array in sub-6GHz mobile handset for LTE bands 42/43/46 applications. IEEE Access 2018;6:344-54.

[61] Rappaport TS, et al. Millimeter-wave mobile communications for $5 \mathrm{G}$ cellular: It will work! IEEE Access 2013;1:335-49.

[62] Alibakhshikenari M, et al. High performance metasurface-based on-chip antenna for terahertz integrated circuits. In: Third international workshop on mobile terahertz systems (IWMTS); 2020. p. 1-4.

[63] Roh W, et al. Millimeter-wave beamforming as an enabling technology for $5 G$ cellular communications: Theoretical feasibility and prototype results. IEEE Commun Mag 2014;52:106-13.

[64] Psychoudakis D, Wang Z, Aryanfar F. Dipole array for mm-wave mobile applications. In: IEEE antennas and propagation society international symposium (APSURSI) 2013; 2013. p. 660-1.

[65] Naqvi A, Lim S. Review of recent phased arrays for millimeter-wave wireless communication. Sensors 2018;18:3194.

[66] Parchin NO, et al. Frequency reconfigurable antenna array for mm-Wave 5G mobile handsets. 9th International conference on broadband communications, networks, and systems, Faro, Portugal, 19-20 September 2018. 2018.

[67] Ullah A, et al. A modified design of phased array antenna for UWB-5G cellular communications. 2020 IMDC-SDSP, Ankara Turkey. 2020.

[68] Li R, et al. Design of a miniaturized antenna based on split ring resonators for $5 \mathrm{G}$ wireless communications. In: Cross Strait Quad-Regional Radio Science and Wireless Technology Conference (CSQRWC); 2019. p. 1-4.

[69] Chen Q, et al. Design considerations for millimeter wave antennas within a chip package. In: IEEE international workshop on anti-counterfeiting, security, identification, Xiamen, China; 2007. p. 13-7.

[70] Parchin NO. Low-profile air-filled antenna for next generation wireless systems. Wirel Pers Commun 2017;97:3293-300. 